\title{
Peramalan Utilisasi Perangkat Jaringan dan Bandwidth dengan Metode Holt-Winters dan Multilayer Perceptron
}

\author{
Muhammad Taufiq $^{1}$, Dedy Sugiarto ${ }^{2}$, Abdul Rochman $^{3}$ \\ ${ }^{1,3}$ Jurusan Teknik Informatika, Fakultas Teknologi Industri, Universitas Trisakti, Jakarta, Indonesia \\ m.taufiq064001800502@std.trisakti.ac.id \\ rochman@trisakti.ac.id \\ ${ }^{2}$ Jurusan Sistem Informasi, Fakultas Teknologi Industri, Universitas Trisakti, Jakarta, Indonesia \\ dedy@trisakti.ac.id
}

Diterima 22 April 2020

Disetujui 17 Juni 2020

\begin{abstract}
Network devices become an important medium for transferring data from one node to another node in the form of switches, routers or network security devices. The reliability of network devices must be maintained both in terms of device resources and bandwidth. The study was conducted by applying the Holt-Winters and Multilayer Perceptron (MLP) method to network device and bandwidth data utilization. The two methods are compared to assess which accuracy is better when applied to network device and bandwidth utilization data by calculating Root Mean Squared Error (RMSE) and Mean Absolute Percentage (MAPE). The results of the measurement of accuracy in the network device testing data, MLP produces a value of RMSE of 5,67 and MAPE of 2.34, and Holt-Winters produces a value of RMSE of 14.56 and MAPE of 2.95. For the results of the measurement of accuracy in the bandwidth testing data with MLP produces a value of RMSE of 0.13 and MAPE of 7.27, and Holt-Winters produces RMSE values of 2.59 and MAPE of 134.31. Based on the results of these measurements it is concluded that the MLP method has a smaller error value compared to the Holt-Winters method applied to network device and bandwidth utilization data with a span of 3 years historical data. Build web application design using Mysql as a Database Management System, Laravel as a web application framework, Pentaho for data integration and $R$ programming for data analysis.
\end{abstract}

Index Terms-Framework Laravel, Holt-Winters Method, , Multi Layer Perceptron, Network Devices and Bandwidth, Pentaho Data Integration, $R$

\section{PENDAHULUAN}

Perangkat - perangkat jaringan seperti switch, router atau perangkat keamanan jaringan harus dikelola dengan baik dan benar. Dalam melakukan tugasnya perangkat jaringan harus memiliki kehandalan dan ketersediaan sumber daya untuk mengirim dan menerima data. Pemanfaatan terhadap data tersebut tentunya akan memudahkan perusahaan untuk membuat perencanaan dan pengalokasian dana untuk kebutuhan teknologi Information Technology
(IT) seperti perangkat jaringan dan bandwidth. Dibutuhkan analisis data terhadap data-data historis utilisasi perangkat dan bandwidth dengan menerapkan metode-metode tertentu, sehingga perencanaan menjadi tepat. Pada perusahaan untuk menentukan kebutuhan kedepannya, belum banyak memaksimalkan penggunaan data mining untuk menganalisa dan meramalkan data-data utilisasi perangkat jaringan dan bandwidth. Untuk itu perlu dilakukan analisis data-data historis pada tahun-tahun sebelumnya lalu meramalkan data yang akan muncul ke depannya.

Penelitian terkait jaringan komputer sebelumnya "Peramalan Kebutuhan Bandwidth Iub Jaringan UMTS dan HSDPA Menggunakan Fuzzy Inference System dan Time Series" dengan hasil Mean Absolute Percentage Error (MAPE) sebesar 20,95\% sedangkan metode FTS memiliki rata-rata MAPE sebesar 11,14\%[1]. Penerapan algoritma Holt-Winters sudah diteliti dengan judul penelitian "Prediksi Kekeringan Menggunakan Metode Holt-Winters Studi Kasus di Wilayah Kabupaten Boyolali” dengan hasil ramalan dengan nilai kesalahan ramalan terkecil bernilai 4,27[2]. Pendekatan selanjutanya dengan menggunakan Neural Network, Learning merupakan kemampuan utama yang mendasar dari Neural Network. Salah satu jenis Neural Network adalah Multilayer Perceptron (MLP), Metode Multilayer Perceptron pernah diteliti dengan judul penelitian "Peramalan harga beras IR64 kualitas III menggunakan metode Multilayer Perceptron, HoltWinters dan Auto Regressive Integrated Moving Average" yang menghasilkan nilai akurasi RMSE 5.67 pada metode MLP[3].

Kedua metode tersebut nantinya akan digunakan untuk meramalkan data-data terkait utilisasi jaringan, dari hasil ramalan kedua metode tersebut, Peneliti membandingkan penggunaan metode Holt-Winters dan Multilayer Perceptron, dengan menilai tingkat 
kesalahan pada kedua metode tersebut, kemudian datadata utilisasi jaringan dan bandwidth dilakukan integrasi data dengan Pentaho Data Integration dari format spreadsheet ke bentuk ekstensi sql pada tabel Database Management System MySQL. Untuk memudahkan dalam pengguna dalam meramalkan data, pengoptimalan model dan melihat hasil ramalan, penulis membangun aplikasi berbasis web dengan menerapkan konsep Model View Controller dengan menggunakan Framework Laravel.

\section{Metodologi Penelitian}

\section{A. Teknik Pengumpulan dan Analisis Data}

Analisis data dapat digambarkan sebagai suatu proses yang terdiri dari beberapa langkah di mana data mentah ditransformasikan dan diproses untuk menghasilkan visualisasi data dan dapat membuat prediksi dengan model yang dipilih berdasarkan data yang dikumpulkan [4]. Langkah-langkah yang dilakukan dalam analisis data perangkat jaringan dan bandwidth:

\section{Data Set dan Ekstraksi Data}

Penulis memperoleh data histori utilisasi perangkat jaringan dan bandwidth perusahaan yang ekstraksi dengan bantuan network monitoring server baik yang diekstrak melalui aplikasi maupun diekstrak dengan manual. Data perangkat jaringan yang telah diekstrak merupakan data rata-rata memory setiap bulannya dari beberapa titik perangkat jaringan di Kantor Pusat Jakarta, mulai dari Januari 2017 hingga Desember 2019. Untuk data bandwidth yang telah diekstrak merupakan data penggunaan ratarata bandwidth yang diterima setiap bulannya pada titik-titik perangkat router pada kantor di daerah, mulai dari Januari 2017 hingga November 2019.

\section{Data Preparation}

Data-data utilisasi perangkat jaringan dan bandwidth memiliki variabel yang bervariasi. Pada Perangkat Jaringan terdapat variabel Average Unreachable, Average CPU usage, Average Response time, Average Memory usage sedangkan pada bandwidth terdapat variabel Average Transmit, Average Receive, Max Transmit, Max Received. Penulis memilih Average Memory usage dan Average Receive untuk diteliti. Dilakukan penormalan terhadap data yang menjadi objek penelitian seperti satuan dan rentang bilangan. Pengoptimalan data sesuai format data time series yang dapat dieksekusi oleh metode peramalan. Setiap data utilisasi perangkat jaringan dan bandwidth lalu dibagi menjadi dua bagian yaitu data training dan data uji, dimana persentase data training adalah $85 \%$ dan data uji 15\%. Data training akan digunakan untuk pembelajaran pola dengan menggunakan Holt-Winters dan Multilayer Perceptron dan data uji akan dilakukan pengukuran akurasi. Berikut data set utilisasi perangkat jaringan pada Tabel 1 dan data set bandwidth pada Tabel 2, dengan penjelasan warna kolom sebagai berikut:

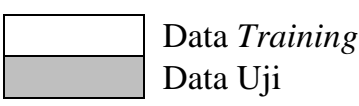

Tabel 1. Data set utilisasi perangkat jaringan

\begin{tabular}{|l|l|c|c|c|}
\hline \multirow{2}{*}{ No. } & \multirow{2}{*}{ Bulan } & \multicolumn{3}{|c|}{ Tahun } \\
\cline { 3 - 5 } & & $\mathbf{2 0 1 7}$ & $\mathbf{2 0 1 8}$ & $\mathbf{2 0 1 9}$ \\
\hline 1 & Januari & 401.79 & 413.10 & 414.81 \\
\hline 2 & Februari & 400.29 & 413.10 & 410.75 \\
\hline 3 & Maret & 406.06 & 416.31 & 421.43 \\
\hline 4 & April & 410.97 & 417.37 & 417.80 \\
\hline 5 & Mei & 411.40 & 419.29 & 417.37 \\
\hline 6 & Juni & 404.56 & 416.52 & 418.65 \\
\hline 7 & Juli & 410.97 & 416.95 & 423.35 \\
\hline 8 & Agustus & 411.61 & 418.87 & 431.25 \\
\hline 9 & September & 410.97 & 418.01 & 436.59 \\
\hline 10 & Oktober & 415.02 & 417.16 & 444.70 \\
\hline 11 & November & 413.96 & 417.16 & 447.26 \\
\hline 12 & Desember & 414.38 & 418.23 & \\
\hline
\end{tabular}

Tabel 2. Data set bandwidth

\begin{tabular}{|l|l|c|c|c|}
\hline \multirow{2}{*}{ No. } & \multirow{2}{*}{ Bulan } & \multicolumn{3}{|c|}{ Tahun } \\
\cline { 3 - 5 } & & $\mathbf{2 0 1 7}$ & $\mathbf{2 0 1 8}$ & $\mathbf{2 0 1 9}$ \\
\hline 1 & Januari & 0.45 & 1.02 & 1.04 \\
\hline 2 & Februari & 0.54 & 0.76 & 0.92 \\
\hline 3 & Maret & 0.41 & 0.51 & 1.32 \\
\hline 4 & April & 0.29 & 0.69 & 1.19 \\
\hline 5 & Mei & 0.17 & 0.51 & 1.07 \\
\hline 6 & Juni & 0.15 & 0.37 & 1.16 \\
\hline 7 & Juli & 0.15 & 0.64 & 1.27 \\
\hline 8 & Agustus & 0.33 & 0.64 & 1.31 \\
\hline 9 & September & 0.65 & 0.91 & 1.50 \\
\hline 10 & Oktober & 0.73 & 0.93 & 1.61 \\
\hline 11 & November & 0.76 & 1.05 & \\
\hline 12 & Desember & 0.84 & 1.16 & \\
\hline
\end{tabular}

3. Metode Peramalan Holt-Winters

Metode Holt-Winters menggunakan tiga parameter pemulusan yaitu konstanta pemulusan, parameter untuk tren, dan parameter untuk musiman. Metode Holt-Winters memiliki keunggulan pada Exponential smoothing bersifat sederhana, intuitif dan mudah dipahami. Sederhana tetapi sangat bermanfaat untuk peramalan pendek dari data time series yang panjang. 
Dilihat dari fluktuasi musiman pada data utilisasi perangkat jaringan dan bandwidth yang bersifat variasi penulis menggunakan model Multiplicative jika besarnya variasi musiman meningkat dengan peningkatan tingkat rata-rata deret waktu[5].

Persamaan dasar untuk model Holt-Winters Multiplicative:

Nilai Pemulusan keseluruhan

$$
L_{t}=\alpha \frac{Y_{t}}{S_{t-s}}+(1-\alpha)\left(L_{t-1}+b_{t-1}\right)
$$

Nilai Pemulusan komponen trend

$$
b_{t}=\beta\left(L_{t}-L_{t-1}\right)+(1-\beta) b_{t-1}
$$

Nilai Pemulusan komponen musiman

$$
\begin{gathered}
S_{t}=\gamma \frac{Y_{t}}{L_{t}}+(1-\gamma) S_{t-s} \\
\text { Nilai Ramalan } \\
F_{t+m}=\left(L_{t}+b_{t} m\right) S_{t-s+m}
\end{gathered}
$$

Data utilisasi perangkat jaringan dan bandwidth setiap bulannya akan diproses pada persamaan model Holt-Winters Multiplicative dengan 3 parameter yang bisa disesuaikan yaitu $(\boldsymbol{\alpha})$ konstanta pemulusan, $(\boldsymbol{\beta})$ parameter trend, dan $(\boldsymbol{\gamma})$ parameter musiman. Untuk mengetahui pola pada data training baik utilisasi perangkat jaringan dan bandwidth. Model yang terbentuk dari penyesuaian parameter konstanta pemulusan, parameter trend dan parameter musiman. Mengihasilkan nilai parameter pemulusan alpha $=0.471$, beta $=0$ dan gamma $=1$ pada utilisasi perangkat jaringan dan dihasilkan nilai parameter pemulusan alpha $=0.881$, beta $=0$ dan gamma $=1$ pada bandwidth.

Selanjutnya dengan nilai parameter yang sudah ditetapkan, penulis melakukan peramalan 5 bulan kedepannya yaitu bulan juli, agustus, september, oktober, november pada data utilisasi perangkat jaringan dan bulan juli, agustus, september, oktober pada data bandwidth.

\section{Metode Peramalan Multilayer Perceptron}

Cara kerja MLP ini mengadopsi jaringan saraf mahluk hidup, sehingga terkenal bagus karena proses pembelajaran yang mampu dilakukan secara terarah. MLP dikembangkan dari Perceptron dimana untuk memcahkan permasalahan yang tidak bisa dipecahkan oleh perceptron. Arsitektur MLP:

- Lapisan Input merupakan lapisan dimana setiap unit nya menyimpan data, pada lapisan input ini akan disimpan data utilisasi perangkat jaringan dan data bandwidth.

- $\quad$ Lapisan Hidden merupakan lapisan diantara lapisan input dan lapisan output, lapisan hidden dapat terdiri dari 1 lapisan atau lebih dari 1, dilakukan pembobotan dari sejumlah input dan bias dimasukkan ke fungsi aktivasi melalui fungsi transfer untuk menghasilkan output.

- Lapisan Output merupakan hasil kalkulasi atau pembelajaran dari lapisan sebelumnya.

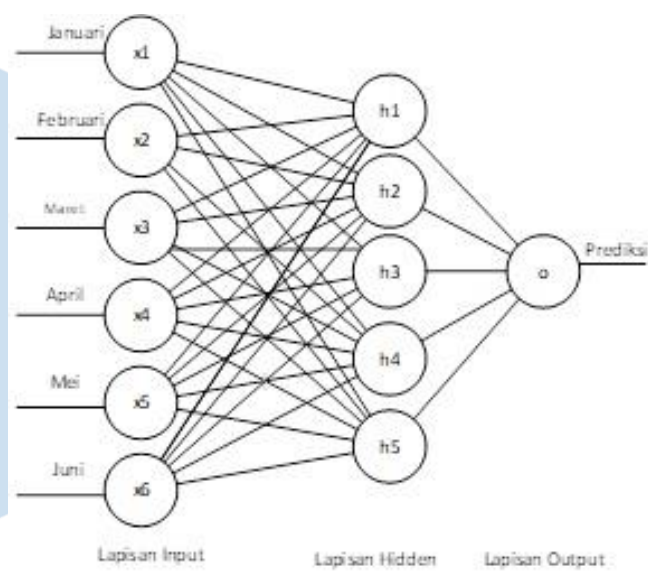

Gambar 1. Arsitektur MLP

Backpropagation merupakan suatu algoritma pembelajaran yang dapat memperkecil tingkat sebuah error dengan bobotnya yang disesuaikan berdasarkan perbedaan dari output dan atau target. Di dalam backpropagation terdapat fungsi aktivasi [6].

Fungsi aktivasi digunakan agar nilai threshold membatasi nilai keluaran agar selalu dalam batas nilai yg ditetapkan. Fungsi yang digunakan adalah sigmoid biner memiliki nilai pada range 0 sampai 1, didefenisikan:

$$
y=f(x)=\frac{1}{1+e^{-x}}
$$

\section{Algoritma Backpropagation}

Inisialisasi semua bobot, lapisan input akan diisi bobot nilai data sesuai bulan secara sequensial, lapisan tersembunyi akan diisi dengan nilai acak. 
a. Tahap Propagasi Maju

Tiap unit input menerima sinyal dan meneruskannya ke unit hidden setelahnya. Tiap unit hidden mendapatkan nilai dengan mengalikan nilai dari tiap unit input dengan bobot menuju pada unit hidden lalu menghitung keluaran di unit hidden dengan fungsi aktivasi. Selanjutnya unit output akan mendapatkan nilai dengan mengalikan nilai dari tiap unit hidden dengan bobot menuju unit output, lalu menghitung keluaran unit di unit output dengan fungsi aktivasi.

b. Tahap Propagasi Mundur

Mengitung faktor $\delta$ unit keluaran berdasarkan error di setiap unit keluaran. Hitung factor $\delta$ unit tersembunyi berdasakan eror di setiap lapisan tersembunyi.

c. Tahap Perubahan bobot

Menghitung semua perubahan bobot. Perubahan bobot garis yang menuju ke lapisan keluaran dan perubahan bobot garis yang menuju ke lapisan hidden.

\section{B. Pengujian dan Pengukuran Akurasi Peramalan}

Pada tahapan pengujian dilakukan pengukuran akurasi terhadap ramalan dengan:

\section{- $\quad$ Root Mean Squared Error (RMSE)}

Pengukuran dengan menggunakan RMSE dengan menghitung nilai akar rata-rata kuadrat kesalahan dari suatu peramalan, dimana $X_{i}$ adalah nilai target aktual, $F_{i}$ adalah nilai keluaran prediksi, dan $\mathrm{n}$ adalah jumlah baris data.

$$
R M S E=\sqrt{\left(\left(\sum_{i=1}^{n}\left(X_{i}-F_{i}\right)^{2}\right) / n\right)}
$$

- $\quad$ Mean Absolute Percentage Error (MAPE)

Metode ini dihitung dengan menggunakan kesalahan yang absolut pada setiap periode lalu dibagi dengan nilai penelitian atau observasi yang nyata untuk periode itu. Kemudian, merata-ratakan kesalahan persentase absolut tersebut.

$$
\text { MAPE }=\frac{\sum \frac{\left|e_{i}\right|}{X_{i}} \times 100 \%}{n}=\frac{\sum \frac{\left|X_{i}-F_{i}\right|}{X_{i}} \times 100 \%}{n}
$$

\section{Pengkodean Program \\ C.1 Pengkodean pada $\mathrm{R}$}

Pada tahapan ini dilakukan pengkodean program untuk implementasi dari metode algoritma peramalan dan mendapat akurasi dari tingkat peramalan. Untuk metode peramalan dengan Holt-Winters dapat dilihat pada Listing 1 dan untuk metode peramalan dengan Multilayer Perceptron dapat dilihat pada Listing 2. Data set akan dimasukan ke dalam program (1)berisi tentang data-data utilisasi perangkat jaringan dan bandwidth. Kemudian akan dibuat pemisahan data untuk data training sebanyak $85 \%$ dari data set(3). Pendefinisian data training yaitu dimulai dari data awal hingga data batas training (4). Didefinisikan juga data uji yang dimulai dari data batas training hingga jumlah data yang diinput(5). Pendefinisian variabel ramal dengan nilai kosong dan juga variabel history yang diisi dengan data training $(6,7)$. Dilakukan peramalan dengan fungsi pengulangan dengan batas banyaknya data pada data testing (8). Masing-masing data training disesuaikan dengan model peramalannya, penyesuaian parameter alfa $(\alpha)$, beta $(\beta)$ dan gamma $(\gamma)$ pada Holt-Winters, dan penyesuaian lapisan input, hidden, dan output pada MLP (9). Dilakukan pemodelan untuk menemukan model yang paling optimal pada data training dengan menyesuaikan parameter yang ada pada model (10). Dilakukan peramalan ke $\mathrm{x}$ dengan menggunakan model yang paling optimal (11), kemudian nilai ramalan ke $\mathrm{x}$ diappend ke dalam variabel ramal (12). Data testing ke $\mathrm{x}$ lalu lalu dimasukan kedalam variable observasi(13). kemudian nilai observasi di masukan kedalam variabel history untuk (14). Nilai yang ada pada variabel observasi di append kedalam variabel history, sebagai penanda batas terakhir permalan pada pengulangan for selanjutnya. Dilakukan pengulangan (9...14) sampai nilai x sama dengan nilai banyaknya data pada data testing. Setelah data-data ramalan didapat, lalu dilakukan pengukuran akurasi peramalan dengan menggunakaan Mean Squared Error dengan mengunakan data testing dan data ramal (16), setelah itu dilakukan akar untuk menghasilkan nilai RMSE (17). Dilakukan perhitungan akurasi juga menggunakan Mean Absolute Percent Error (MAPE) (18).

Listing 1. Pseudo code peramalan Holt-Winters

$\quad$ \#Proses Data
(1)Inputs: data
(2)Output: RMSE dan MAPE dari peramalan data
\#Data Preperation
(3)batas <- length(data)*0.85
(4)training <- series[0...batas]
(5)testing <- series[batas...length(data)
(6)ramal<- empty
(7)history <- training
\#Model dan Peramalan
(8) For each x in range(length(testing)) do
(9) model <- Holt-Winters(training, alfa, beta,
gamma, Multiplicative)
(10) model_fit<- model.fit()
(11) nramal<- model_fit.forcast()


(12) ramal.append(nramal)

(13) observasi <- testing[x]

(14) history.append(observasi)

(15) end for

$$
\text { \#Pengukuran Akurasi }
$$

(16) $\mathrm{MSE}=$ mean_squared_error(testing,ramal)

(17) $\mathrm{RMSE}=\operatorname{sqrt}(\mathrm{MSE})$

(18)MAPE=mean_absolute_percent_error(testing, ramal)

\section{Listing 2. Pseudo code peramalan MLP}

(1)Inputs: data

$$
\text { \#Proses Data }
$$

(2)Output: RMSE dan MAPE dari peramalan data

\section{\#Data Preperation}

(3)batas <- length (data) $* 0.85$

(4)training <- series[0...size]

(5)testing <- series[batas...length(data)

(6)ramal<- empty

(7)history <- training

\#Model dan Peramalan

(8)For each $\mathrm{x}$ in range(length(testing)) do (9)model <- mlp(training)

(10)model fit $<$ - model.fit()

(11) nramal <- model_fit.forcast()

(12) ramal.append(nramal)

(13) observasi <- test [t]

(14) history.append(observasi)

(15) end for

\#Pengukuran Akurasi

(16) $\mathrm{MSE}=$ mean $\_$squared_error(test,ramal)

(17) RMSE $=\operatorname{sqrt}($ MSE)

(18)MAPE = mean_absolute_percent_error

\section{C.2 Laravel dan Model View Controller (MVC)}

Framework Laravel menggunakan kerangka kerja pengembangan web MVC yang ditulis dalam bahsa pemograman PHP. Dirancang untuk meningkatkan kualitas perangkat lunak dengan mengurangi biaya pengembangan awal dan biaya perawatan yang berkelanjutan, dan untuk meningkatkan pengalaman bekerja dengan aplikasi kita dengan menyediakan sintaksis mudah yang jelas dan serangkaian fungsionalitas inti yang akan menghemat waktu dalam implementasi [7]. Berikut konsep arsitektur MVC pada Laravel pada Gambar 2.

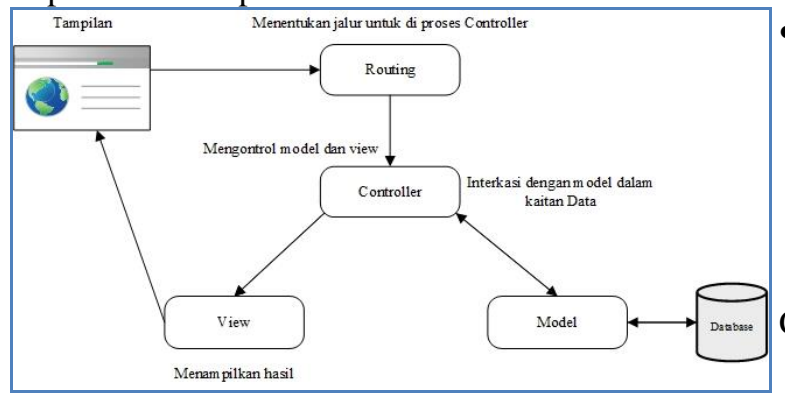

- Selanjutnya digunakan fitur migration pada Laravel sehingga dimungkinkan untuk membuat dan memodifikasi tabel yang ada pada basisdata sesuai dengan kerangka model yang telah dibuat pada proses sebelumnya.

php artisan migrate

\section{C.3.2 View}

Bagian presentation logic merupakan bagian penting dalam aplikasi. Pada suatu aplikasi web, 
bagian ini biasanya berupa file template HyperText Markup Language, yang diatur oleh controller. view bertugas untuk menerima dan merepresentasikan data hasil dari model dan controller kepada pengguna aplikasi. Pada aplikasi web disediakan halaman untuk melakukan peramalan dan menampilkan hasil ramalan data.

\section{C.3.3 Controller}

Ketika pengguna aplikasi melakukan request data dengan mengklik link, maka controller akan melakukan pemanggilan ke model untuk mendapatkan data yang sesuai, dan kemudian mempersiapkan data tersebut untuk ditampilkan. File controller di letakkan pada folder lapp/Http/Backend/AnalisisController.php dengan kode program yang dapat dilihat pada Gambar 4.

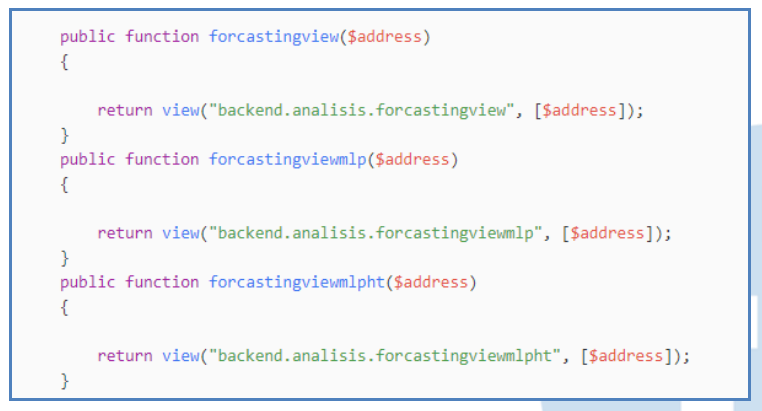

Gambar 4. Kode program pada AnalisisController

\section{C.3.4 Routing}

Routing merupakan suatu proses untuk mengarahkan suatu permintaan atau item agar sampai pada tujuan. Fungsi routing pada Laravel terletak pada direktori web.php dengan kode program pada aplikasi web yang dapat dilihat pada Gambar 5.

oute: 'get('/backend/analisis/forcastingview/\{id\}', 'BackendlAnalisiscontrollengforcastingview');

Route: : get('/backend/analisis/forcastingvieumlp/(\{id\}', 'Backend/Analisis controllenọforcastingvieumlp');

Route: :get('/backend/analisis/forcastingvieumlpht/\{id\}', 'BackendlAnalisiscontrolleregforcastingvieumlpht');

Gambar 5. Kode pada web.php

\section{C.3 Integrasi Data}

Setelah data di-cleansing, tahap selanjutnya melakukan transformasi format data spreadsheet, penyesuaian terhadap struktur nama kolom dan pengisian data kosong pada data set serta bagaimana mengubahnya dalam format structured query language sehingga data dapat di load kedalam MySQL bersama dengan recordsnya. Berikut skenario transform data yang terlihat pada Gambar 6 .

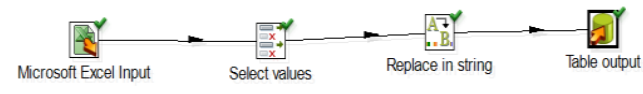

Gambar 6. Skenario transform data

\section{C.3.1 Microsoft Excel Input}

Pada tahap ini dilakukan penarikan data utilisasi jaringan dan bandwidth ke dalam Lembar kerja Pentho Data Integration.

\section{C.3.2 Select Values}

Pada tahap ini dilakukan perubahan header kolom pada tabel dengan nama sesuai dengan field nantinya pada MySQL, sehingga diperlukan transformasi terhadap header datanya. Penyesuaian dilakukan agar membuat penyeragaman struktur field, sehingga nantinya memudahkan dalam pengkodean dengan Framework Laravel.

\section{C.3.3 Replace In String}

Pada tahap ini dilakukan perubahan nilai record yang tidak memiliki nilai atau memiliki string “_.“ dengan mengganti nilai tersebut dengan " 0 ”. Hal ini dilakukan agar tidak ada data yang kosong, untuk selanjutnya diberikan nilai 0 .

\section{C.3.4 Table Output}

Pada tahap ini dilakukan pembuatan field sesuai struktur tabel yang telah di proses sebelumnya dan ekstraksi records ke dalam bentuk sql. Berikut hasil integrasi data pada Gambar 7 dan records pada MySQL pada Gambar 8.

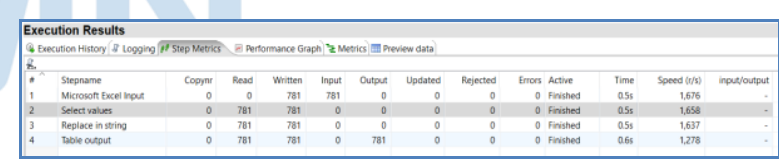

Gambar 7. Log hasil transformation

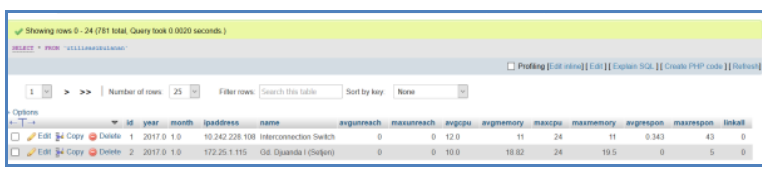

Gambar 7. Records pada $M y S Q L$

\section{C.4 Visualisasi Data pada Antarmuka Web}

Dalam melakukan visualisasi data diperlukan fungsi untuk membuat grafik, fungsi tersebut ada pada program $\mathrm{r}$ yang biasa digunakan adalah plot. 
Untuk melakukan hal tersebut diperlukan skenario pada Gambar 9 untuk dapat menampilkan grafik data pada antarmuka web.

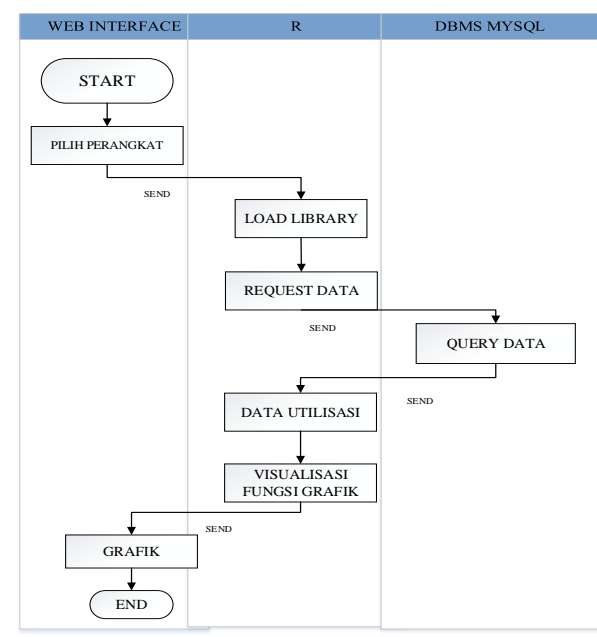

Gambar 9. Skenario visualisasi plot

Untuk dapat menampilkan output pada $\mathrm{R}$ pada antarmuka web dilakukan editing kode program seperti pada sintaks dibawah ini dengan bantuan fungsi $\operatorname{sink}()$ :

sink("htdocs/NetworksControllerv5/public/backend/ht data.txt")

show(timeseries.all)

show(timeseries.training)

show(timeseries.uji)

fitht.timeseries

fitht.timeseries\$fitted

htcast

$\operatorname{sink}() \#$ stop sinking, $=\operatorname{sink}(N U L L)$

\section{HASIL DAN ANALISIS}

Pada plot data Average Memory dan data bandwidth seperti yang terlihat pada Gambar 10 dan Gambar 11. Utilisasi perangkat jaringan dan bandwidth cenderung naik di bulan Juni-Desember. Hal tersebut dipengaruhi dengan pengaksesan konten-konten yang semakin banyak pada bulan tersebut. Konten-konten yang dimaksud adalah konten terkait kegiatan dalam implementasi Indikator Kinerja Utama (IKU) pada unit, yang semakin banyak menggunakan aplikasi-aplikasi elektronik office dan aplikasi proses bisnis. Hal yang paling rawan adalah interval oktober hingga desember, karena pada bulan tersebut penutupan anggaran tahunan.

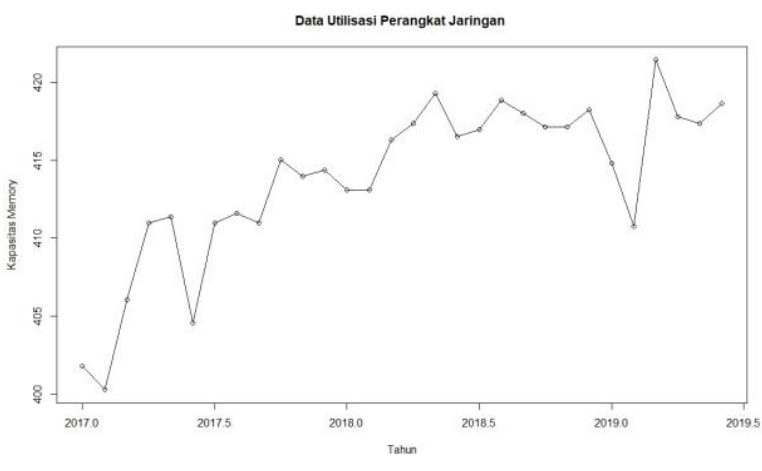

Gambar 10. Data training utilisasi perangkat jaringan

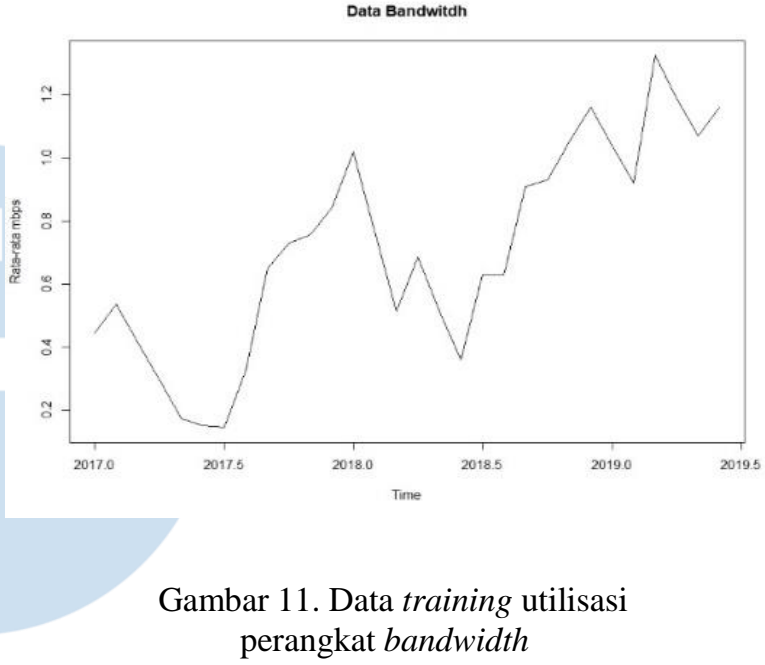

Peramalan dengan menggunakan metode HoltWinters pada data utilisasi perangkat jaringan menghasilkan nilai parameter pemulusan alpha = 0.47 beta $=0$, dan gamma $=1$. Pada Gambar 12 terlihat model yang dihasilkan menyesuaikan pola pada data training utilisasi perangkat jaringan.

Peramalan dengan menggunakan metode HoltWinters pada data bandwidth menghasilkan nilai parameter pemulusan alpha $=0.88$, beta $=0$, dan gamma $=1$. Pada Gambar 13 terlihat model yang dihasilkan menyesuaikan pola pada data training bandwidth. 


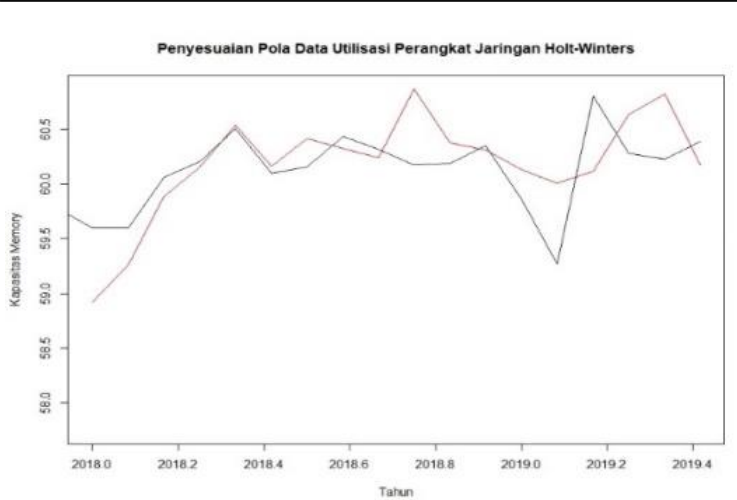

Gambar 12. Penyesuaian parameter data utilisasi perangkat jaringan dengan Holt-Winters

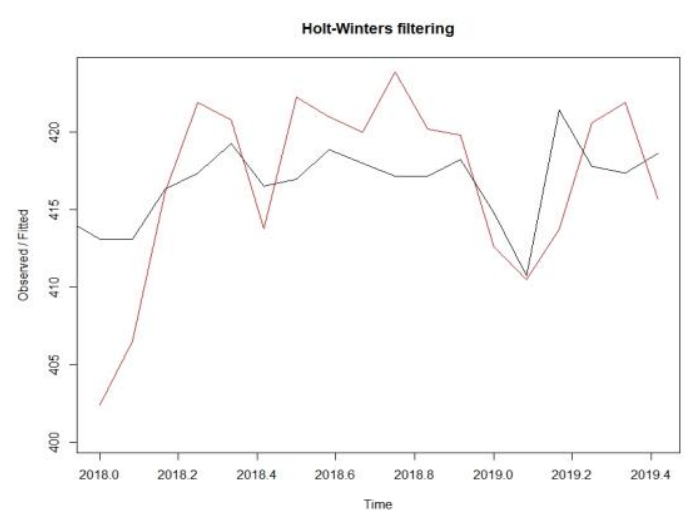

Gambar 13. Penyesuaian parameter data bandwith dengan Holt-Winters

Peramalan dengan menggunakan metode MLP pada data utilisasi perangkat jaringan menghasilkan model lapisan 6-5-1 pada Gambar 13 dimana 6 unit pada lapisan input, 5 unit lapisan hidden, dan 1 unit pada lapisan output. Data training utilisasi perangkat jaringan akan diformulasikan dengan model tersebut untuk mendapat nilai peramalan. Peramalan dengan menggunakan metode MLP pada data utilisasi perangkat jaringan menghasilkan model lapisan 12-51 pada Gambar 15 dimana 12 unit pada lapisan input, 5 unit lapisan hidden, dan 1 unit pada lapisan output. Data training utilisasi perangkat jaringan akan diformulasikan dengan model tersebut untuk mendapat nilai peramalan.

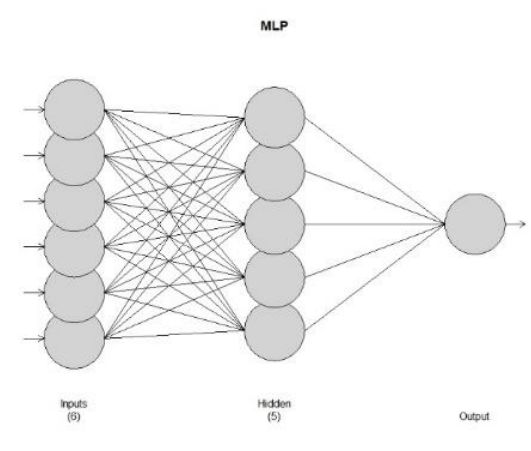

Gambar 14. Struktur model MLP pada data utilisasi perangkat jaringan

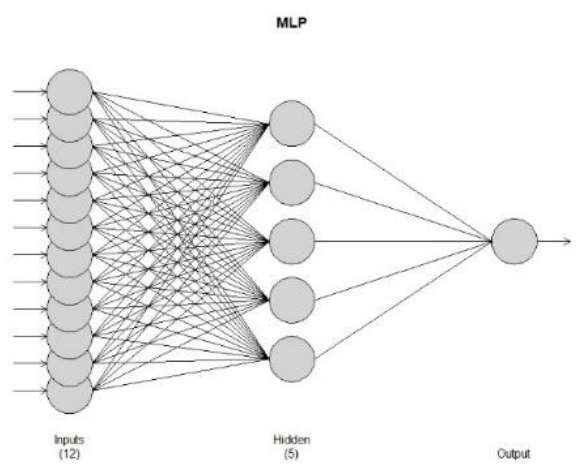

Gambar 15. Struktur model MLP pada data bandwidth

Hasil peramalan dengan menggunakan Holt-Winters dan MLP pada data utilisasi perangkat jaringan dan data bandwidth pada Tabel 3.

Tabel 3. Tabel hasil peramalan

\begin{tabular}{|l|l|c|c|c|}
\hline \multirow{2}{*}{ Data } & Bulan & $\begin{array}{c}\text { Data } \\
\text { Aktual }\end{array}$ & $\begin{array}{c}\text { Ramalan } \\
\text { MLP }\end{array}$ & $\begin{array}{c}\text { Ramalan } \\
\text { Holt- } \\
\text { Winters }\end{array}$ \\
\hline \multirow{4}{*}{$\begin{array}{l}\text { Data } \\
\text { Utilisasi } \\
\text { Perangkat } \\
\text { Jaringan }\end{array}$} & July & 423.35 & 426.27 & 420.00 \\
\cline { 2 - 5 } & Agust & 431.25 & 420.96 & 422.95 \\
\cline { 2 - 5 } & Sep. & 436.59 & 421.85 & 423.01 \\
\cline { 2 - 5 } & Okt & 444.7 & 429.92 & 425.32 \\
\cline { 2 - 5 } & Nov & 447.26 & 438.76 & 426.77 \\
\hline \multirow{3}{*}{$\begin{array}{l}\text { Data } \\
\text { Bandwidth }\end{array}$} & Juli & 1.27 & 1.30 & 1.18 \\
\cline { 2 - 5 } & Agust & 1.31 & 1.25 & 2.28 \\
\cline { 2 - 5 } & Sept. & 1.50 & 1.35 & 4.71 \\
\cline { 2 - 5 } & Okt & 1.61 & 1.40 & 5.58 \\
\hline
\end{tabular}

Dilakukan pengukuran akurasi peramalan pada data uji dengan menggunakan RMSE dan MAPE pada Tabel 4 akurasi peramalan. 
ISSN 2085-4552

Tabel 4. Akurasi ramalan

\begin{tabular}{|l|l|l|l|}
\hline Data & $\begin{array}{l}\text { Metode } \\
\text { Ramalan }\end{array}$ & RMSE & MAPE \\
\hline $\begin{array}{l}\text { Data Utilisasi } \\
\text { Perangkat } \\
\text { Jaringan }\end{array}$ & MLP & 11.16 & 2.34 \\
\cline { 2 - 4 } & HW & 14.56 & 2.95 \\
\hline \multirow{2}{*}{ Data Bandwidth } & MLP & 0.13 & 7.27 \\
\cline { 2 - 4 } & HW & 2.59 & 134.31 \\
\hline
\end{tabular}

Hasil aplikasi berbasis web dengan Framework Laravel untuk peramalan dengan mengkoneksikan Framework Laravel, R dan MySQL menjadikan aplikasi dapat digunakan oleh user pengguna tanpa melakukan editing kode program pada R. Pada Gambar 16 dapat dilihat tampilan halaman pemilihan metode peramalan dan juga data yang ingin diramalan, pada Gambar 17 dan 18 halaman hasil ramalan Holt-Winters dan MLP, sedangkan pada Gambar 19 visualisasi grafik data histori pada perangkat jaringan.

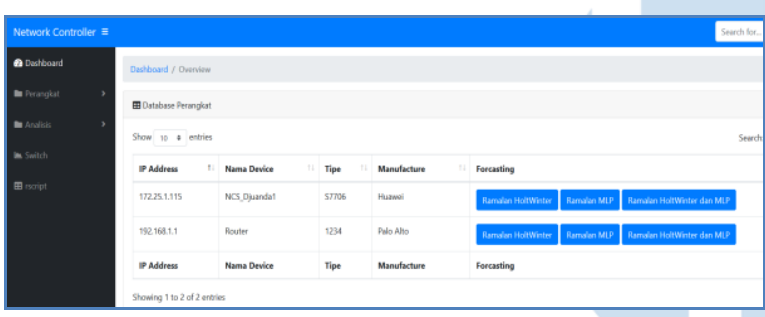

Gambar 16. Halaman pemilihan metode peramalan

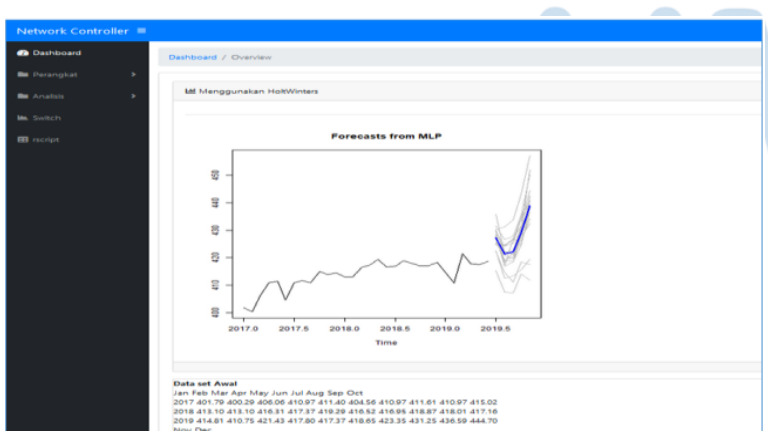

Gambar 17. Halaman hasil ramalan MLP

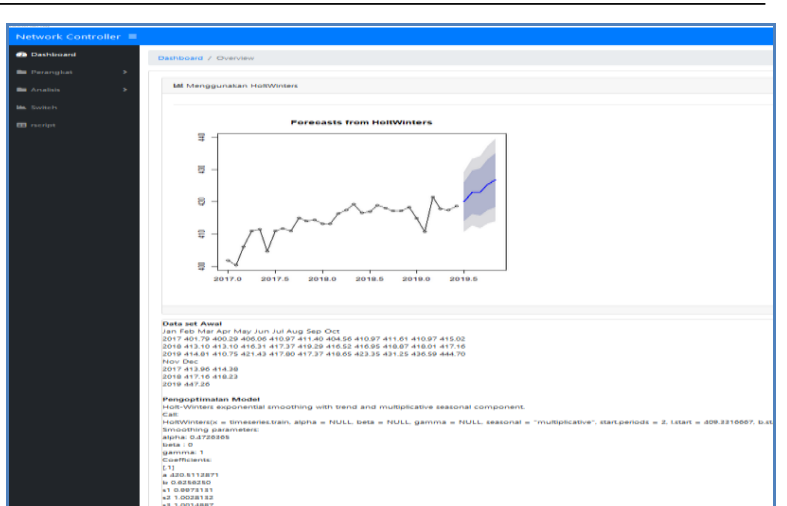

Gambar 18. Halaman hasil ramalan Holt-Winters
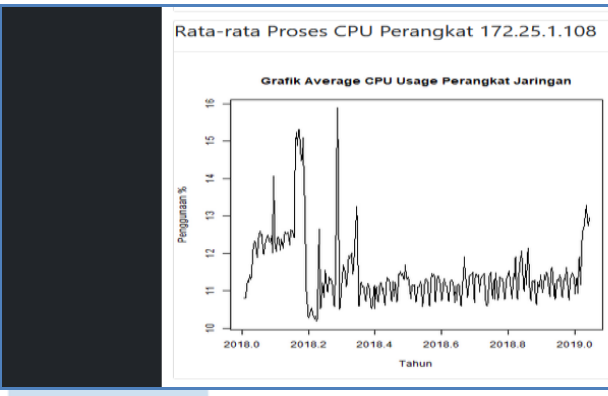

Gambar 19. Halaman grafik utilisasi

\section{SIMPULAN}

Data utilisasi perangkat jaringan dan bandwidth mengalami peningkatan bulan-bulan pada akhir tahun. Berdasarkan pengukuran nilai akurasi menggunakan RMSE dan MAPE terhadap utilisasi perangkat jaringan dan bandwidth didapatkan bahwa metode MLP memiliki nilai kesalahan (error) lebih kecil dibandingkan dengan metode Holt-Winters. Perlu dilihat nilai ambang batas memory pada perangkat jaringan, jika ramalan data melebihi nilai ambang batas, maka menjadi perhatian untuk dievaluasi. Untuk bandwidth perlu diliat kapasitas bandwidth yang disewa, jikalau hasil ramalan data pada bandwidth melebihi perlu dilakukan evaluasi penambahan kapasaitas bandwidth jaringan. Aplikasi berbasis web dengan konsep MVC pada Framework Laravel dapat di visualisasikan hasilnya dalam bentuk grafik dengan dikoneksikan pada program $\mathrm{R}$, hal tersebut dapat mempermudah dalam menggambarkan keadaan dari pemanfaatan sumber daya perangkat jaringan dan peramalan data. Penggunaan Pentaho Data Integration untuk melakukan ekstraksi data yang records-nya banyak dengan format spreedsheet ditransformasikan dan di-load ke dalam MySQL dapat mengefesiensikan waktu pekerjaan. 


\section{DAFTAR PUSTAKA}

[1] A. Wahyu, E. Yudaningtyas, and S. H. Pramono, "Peramalan Kebutuhan Bandwidth Iub Jaringan UMTS dan HSDPA Menggunakan Fuzzy Inference System dan Time Series," J. EECCIS, 2014.

[2] D. A. W. S. Putra, K. D. Hartomo, and R. Tanone, "Model Prediksi Kekeringan Menggunakan Metode HoltWinters (Studi Kasus: Wilayah Kabupaten Boyolali)," Indones. J. Comput. Model., 2018, doi: 10.24246/j.icm.2018.v1.i1.p36-41.

[3] A. B. Ariwibowo, D. Sugiarto, I. A. Marie, and J. F. Agatha, Peramalan harga beras IR64 kualitas III menggunakan metode Multilayer Perceptron, HoltWinters dan Auto Regressive Integrated Moving Average, vol. XI. 2019.

[4] F. Nelli, Python Data Analytics. New York: Apress,
2015

D. C. Montgomery, C. L. Jennings, and M. Kulahci, Introduction Time Series Analysis and Forecasting, Second. New Jersey: John Wiley \& Sons, Inc., 2016.

[6] Y. A. Lesnussa, S. Latuconsina, and E. R. Persulessy, "Aplikasi Jaringan Saraf Tiruan Backpropagation untuk Memprediksi Prestasi Siswa SMA (Studi kasus: Prediksi Prestasi Siswa SMAN 4 Ambon)," J. Mat. Integr., 2015, doi: 10.24198/jmi.v11.n2.9427.149-160.

[7] S. McCool, Laravel Starter. Birmingham: Packt Publishing, 2012.

[8] Chandra Shekhar, "General architecture of Laravel based application Chandra Shekhar Pandey." [Online]. Available: http://www.cutehits.com/2017/06/generalarchitecture-of-laravel-based-application/. [Accessed: 21Apr-2020]. 